\title{
Uma comunicação de limiaridades: imagens, fabulações e seus efeitos cotidianamente espetaculares
}

\begin{abstract}
(...) as mais verdadeiras e as mais intensas das afeições humanas sãs as que brotam no coração como por uma simpatia elétrica; em uma palavra: (...) as mais brilhantes e as mais resistentes cadeias psíquicas são as forjadas por um olhar.
\end{abstract}

Edgar Allan Poe

Somos seres olhados no espetáculo do mundo. O que nos faz consciência nos institui, do mesmo golpe, como speculum mundi.

Jacques Lacan

\section{RESUMO}

Análise de algumas teorias contemporâneas da imagem aplicadas ao campo da comunicação. Problematização da relação analítica adotada no estudo das imagens, avaliando o grau de interação e autonomia da escrita em contraponto à crescente autonomização das imagens no contexto comunicacional na atualidade. Abordagem das interfaces e tensões entre imagem e cotidiano presentes na produção e no consumo de produtos da indústria do entretenimento voltados à representação do banal e do comezinho.

\section{PALAVRAS-CHAVE}

- imagem

- mídia

- comunicação

\section{ABSTRACT}

Analysis of some contemporary image theories applied to the field of communication. Analytical relation adopted in the study of images is discussed, evaluating the degree of interaction and autonomy of writing in counterpoint to the increasing autonomy of images in the present communicative context. The article focuses on the interfaces and tensions between image and everyday life in the production and the consumption of products of the entertainment industry directed to the representation of banalities.

\section{KEY WORDS}

- image

- media

- communication

\section{Rose de Melo Rocha ESPM/SP}

0 estudo das imagens, da produção de visualidades e dos agenciamentos midiáticos da visibilidade social, desde um ponto de vista comunicacional, vem, por muitos anos, mobilizando minhas preocupações e investigações acadêmicas. Verdadeiras obsessões cognitivas. Consentida colonização imagética. Por vezes o encantamento. Aqui e acolá o arrebatamento. Em outras situações a embriaguez do excesso. Mais um pouco e o consumo compulsório beira a recusa, a rejeição, o que vejo pode profundamente me indignar. $\mathrm{O}$ mais puro caso de imagem, imaginem só.

Inevitavelmente tributária deste trajeto, aqui resgatarei reflexões sobre as imagens limiares - ou sobre o fato de elas se apresentarem em situação de limiaridade: no limite do público e do privado, do factual e do ficcional, do documental e do espetacular, do informativo e do entretenimento, do consumo e da consumação, do espetacular e do banal, entre outros. Algumas das hipóteses ora apresentadas já foram partilhadas com colegas da área em encontros acadêmicos nacionais, mas ainda não estavam publicadas.

Este ensaio acadêmico, em consonância com um método bastante particular de observação e narrativa sobre e com imagens, está ancorado em aportes teórico-metodológicos específicos. Em um primeiro momento, discutirei, tendo por inspiração uma narrativa literária, as limiaridades que se caracterizam como ato de fabulação, dimensão mágica e imaginária inerente à experimentação das imagens. A percepção que se construirá sobre a cultura da visualidade articula-se a uma preocupação de fundo, que neste trabalho não tornarei explícita, sobre a natureza mesma da limiaridade em uma sociedade de consumo que, cada vez mais, articula-se em torno de processos imagéticos e daquilo que autores como Kroker e Cook (1986) chamam de uma "ideologia do entretenimento" e de um processo de "fixação de estados de espírito".

Em uma segunda etapa reflexiva, defenderei exatamente uma leitura comunicacional de alguns fenômenos e produtos de entretenimento articulados a estratégias de visibilização de cenas do dia-a-dia. Propõe-se, com tal objetivo, a apresentação de um mapeamento sucinto de operadores conceituais de análise de representações imagéticas da vida cotidiana em contextos contemporâneos.

Como horizonte epistemológico norteador destes eixos interpretativos, assume-se a consideração das dimensões antropológicas, ancestrais e memoriais constituintes da produção e do consumo de produtos comunicacionais, sejam eles massivos ou associados 
a uma cultura propriamente midiática, de difusão maciça e caráter muitas vezes segmentado ou personalizado. Tal perspectiva - em sintonia com concepções historicamente demarcadas de crítica cultural não descarta, obviamente, a inclusão de matizes periodizantes, capazes de dar conta de componentes que na atualidade caracterizam o modo de aparecimento dos fenômenos imagéticos estudados.

\section{Verdades, inverdades e uma percepção sempre fabulada}

Desejo escrever sobre imagens, estas poderosas mediadoras de nossa comunicação conosco, com os outros, com o mundo no qual vivemos e com aqueles tantos que menos ou mais deliberadamente forjamos.

Desejo escrever sobre imagens. A sentença possui caráter performativo. Mal a escrevo e já estou absolutamente entregue, literalmente submersa em inúmeras e múltiplas visualidades. Começo a achar que imagens não gostam de ser escritas. Penso que elas se divertem com meu esforço e me devolvem, irônicas, a sua potente sedução. Venha, elas pedem, venha lembrar-se de como nós, as imagens, te povoamos. Lembre-se, minha cara, do que falava aquele autor que tanto te agrada: já somos, de fato, algo como uma nova naturalidade ${ }^{1}$. Venha, aceite que comandamos todos os teus cenários e não queira, você, inscrever-nos nas suas inscrições.

Teimo, mas também constato. A astúcia dos objetos, longamente teorizada por autores como Jean Baudrillard $(1983 ; 1990)$ encontra sua melhor expressão nestas curiosas existências limiares que trafegam desenvoltas entre o natural e o artifício. Encontro-me, ao escrever, deitada sobre imagens, dançando entre imagens, imaginando imagens e por elas sendo imaginada. Ou seria imageada?

O caminho desta escrita constituiu-se em um percurso de hibridização entre meu desenho cognitivo e aquele que foi sendo traçado por imagens que me povoam. O estranhamento é princípio fundamental de resistência em um mundo que nos interpela com a desconfiança e nos acena a desistência. Estranhar-se e surpreender-se, esta é a atitude com a qual enfrento e componho o espírito de meu tempo. Um tempo povoado por imagens. Elas me povoam. A elas devolvo meu imaginário. É este o exercício de meu olhar.

Tomando pelos olhos meu desavisado leitor, vou permitir-me levá-lo ao encontro de algumas das visuais recordações que foram aderindo à minha escrita. $\mathrm{E}$ esta é uma escrita sobre e com imagens. Creia-me, leitor, eu não sucumbi. Ao menos não totalmente. Mas prossiga comigo. Sou eu quem lhe falo: comecemos por um mergulho literário. Se seguirmos à sugestão do atormentado Gengê ${ }^{2}$, memorável personagem de Luigi Pirandello (s/d), veremos confirmada uma interessante tese sobre a natureza fabuladora e parcial de nosso olhar.

Gengê é um dia surpreendido por sua imagem - de defeitos e qualidades para ele inimagináveis - desve- lada através dos olhos da mulher amada. Aturdido, não muito tarda a se deixar capturar pelo imponderável: nunca lhe será permitido conhecer aquela que seria sua "verdadeira" imagem. Tenta, sem sucesso e por inúmeras vezes, capturar-se sem disfarces diante do espelho. Tarefa inglória. Tenta, ainda, expurgar as características que lhe foram imputadas quando, ao nascer, é-lhe atribuído nome e sobrenome. Mais uma vez fracassa.

Sofridamente, o que o personagem percebe diz respeito ao caráter essencialmente falho e inexoravelmente subjetivo que acomete a construção identitária dos humanos. E a acomete exatamente porque, uma vez humanos, também uma vez enlaçados por olhares, por estes construtos visuais que interpelam tanto videntes quanto visíveis. Sobre isto também nos fala Gengê:

\begin{abstract}
Vocês acreditam que podem conhecer a si mesmos sem se construírem de algum modo? E que eu possa conhecê-los sem construí-los um pouco a meu modo? E vocês a mim, sem me construírem a seu modo? Podemos conhecer apenas aquilo a que conseguimos dar forma. (...) Por que vocês acham que se recomenda tanto a firmeza de vontade ou a constância nos sentimentos? Basta que esta vacile um pouco, ou que aquela se altere um ponto e mude minimamente... e adeus nossa realidade! Subitamente nos damos conta de que tudo não passava de uma ilusão nossa. (Pirandello, s/d: 65-6).
\end{abstract}

Imagens falam também de representações impossíveis. Lyotard (1988), de modo brilhante, relata em minúcias o alcance e a trágica destruição historicamente operada pelas políticas de esquecimento. E estas o são, essencialmente, políticas de imagens, imagens que desconstróem memórias e naufragam imaginários.

\section{Não há mais sociedade, escarneiam Kroker e Cook, esta deu lugar a uma cultura da significação fundada na introjeção do tecnicismo.}

A desconstrução opera-se igualmente pela evocação, por estas esplendorosas e insistentes políticas de aparecimento levadas a cabo pela cultura das mídias. Paul Virilio (1976), com sua verve irônica-denuncista aponta a inequívoca equação que acomete a todos nós, cidadãos dromocráticos ${ }^{3}$ : "onde estou, se estou em toda parte"?

Sou eu o que vejo no espelho, de manhã, ao, sono- 
lenta, escovar os dentes? Sou o que escrevo, sou as imagens que de mim capturaram as câmeras do telejornal local, as fotografias inesperadas colhidas pelas câmeras dos celulares de meus amigos e inimigos, sou mais verdadeiramente eu no click da polaroid, no instantâneo abrigado na carteira de motorista, nos desapercebidos registros do circuito interno de tevê instalado no prédio em que moro? Onde estou, se virtualmente posso estar em toda e qualquer parte? Talvez somente as imagens conheçam minha verdade. E certamente a guardam para si.

Como seria o mundo se escrito apenas através de imagens? Como seria minha vida se descrita apenas através de representações visuais? Um verão em Paris. Uma deliciosa tarde em Montmartre. Uma irrecusável oferta de registro de minha imagem e um consumado retrato, que agora penduro na parede de meu quarto de dormir. Feito sob protestos do jovem retratista, pois, segundo me dizia, era praticamente impossível desenhar alguém que simplesmente não parava quieta. Pose! Era o que ele ordenava. Raimond, o retratista francês, confirmava, sem o saber, outra hipótese de Gengê:

Porque para se ver é preciso fechar a vida em um átimo. Como diante de uma máquina fotográfica. A senhora assume uma pose. E posar é se tornar uma estátua por um momento. A vida se move continuamente e nunca pode ver a si mesma. (...) Mas eu vejo uma imagem da senhora que é só minha - uma imagem que certamente não é a sua. (...) A senhora só pode reconhecer-se posando: estátua sem vida. Quando alguém vive, vive sem se ver. Conhecer-se é morrer. A senhora fica tanto tempo se olhando neste espelho, em todos os espelhos, porque não vive. Não sabe, não pode ou não quer viver. Quer se conhecer em excesso e não vive. (Pirandello, s/d: 199).

Com esta emblemática fala de Gengê desejo direcionar a narrativa para um questionamento mais específico: qual seria o campo possível de acontecimento do olhar em tempos de hiper-exposição e de grande produção imagética? Começo comentando uma tese que encontra sua formulação mais incisiva em Kroker e Cook (1986:267-279), pesquisadores interessados em refletir sobre imagens engendradas em cenários pósmodernos.

Estudando as interseções entre cultura excremental, estetização do real, deterioração das superfícies (como a do corpo), simulação e consumo, estes autores defendem, aos moldes de Umberto Eco, mas principalmente inspirados em Jean Baudrillard, que $a$ tevê é hoje o mundo real, desbancando as teses pregressas de sua consideração como "espelho da sociedade" ou reprodução eletrônica de interesses ideológicos. Ultrapassando a dimensão de mero aparato técnico para se tornar aparato social abrangente, a tevê exemplifica o que seria a constituição de um mediascape cuja exten- são tende à totalização. Agora, eles insistem, $a$ sociedade é que é o espelho da tevê, esta cuja grande ideologia é o entretenimento.

Kroker e Cook permitem-nos chegar a uma sorte de formulação teórica do cenário mediático que não descarte a problematização da exclusão. A “teoria pânico" proposta pelos pesquisadores põe em relevo a lógica predatória de funcionamento deste mediascape, no qual tudo que "escapa" torna-se social e culturalmente periférico. O fosso entre uma massa silenciosa e uma elite igualmente empobrecida, de um ponto de vista identitário, mas visualmente "falante" reporta, no domínio audiovisual, à senha de acesso necessária para nos sentirmos vivos: "TV or Not TV".

Não há mais sociedade, escarneiam Kroker e Cook, esta deu lugar a uma cultura da significação fundada na introjeção do tecnicismo. O existencialismo mediático que se nutre tanto da serialização da cultura quanto da mediatização irreversível do self é, nos termos de Kroker e Cook, a base de uma falsa socialidade. Contentamo-nos com nossos espectros vazios que se exibem no espelho invertido da tevê, conectamonos a este sistema nervoso eletrônico, gigante e exteriorizado, eles dizem, o mesmo que nos diverte o olhar ante o empobrecimento do dia-a-dia na sociedade tecnológica e nos oferece, em troca, simulacros de estilos-de-vida.

Pobre e visionário Gengê, já aturdido em um universo que desconhecia o imaginário da tela. Afinal, como diz Baudrillard (1997),

A sociedade primitiva tinha suas máscaras, a sociedade burguesa, seus espelhos, nós temos nossas imagens. (...) O milagre hoje é que as aparências, por muito tempo reduzidas a uma servidão voluntária, voltam-se na nossa direção, e contra nós, soberanas, através da própria técnica de onde a tínhamos expulsado. (Baudrillard, 1997: 30).

Tenho em mente, ao fazer este comentário, a dimensão da ruptura, operada na linguagem mediática, entre as imagens/sons veiculados, ou seja, o produto final oferecido, e o que, supostamente, seria o "real" retratado. Poderíamos recorrer às teorias da simulação, acatando as ressalvas feitas por Jean-Louis Weissberg (1993:117) - "a operação da simulação nunca cessou", "cada época teve seus simulacros" - e por Philippe Quéau, através de sua noção de preter-real:

Quanto mais se desenvolvem os instrumentos de mediação cognitiva, mais eles têm a tendência a se substituírem à realidade que deveriam ajudarnos a perceber. (...) Esta realidade ao lado da realidade possui inegáveis vantagens - cognitivas, expressivas, lúdicas - mas ela apresenta também novos riscos. O perigo mais aparente é de acreditar tanto nos simulacros que se acaba por tomá-los por reais. (...) A fuga do verdadeiro real 
e o refúgio num real de síntese vão (...) fornecer a milhões de ociosos forçados alucinações virtuais, drogas visuais capazes de ocupar espíritos e corpos (Quéau, 1993:97).

Se for possível, como o fizeram, entre outros, Baudrillard, Kroker e Cook, adotar a noção de simulacro em termos de sua irradiação sócio-cultural, percebemos que o controle, sugerido por Queáu e enfatizado por pesquisadores do porte de Deleuze e Virilio, é, assim, também um controle de segundo grau, um "preter-controle" forjado, como descreve Virilio, no seio de uma sociedade da televigilância e da telepresença. E, neste caso, não é de se estranhar o fascínio por este "olhar pelo olho do vídeo" explorado tanto em estratégias de vigilância propriamente dita quanto, num extremo não tão oposto, nas redes de tevê, na veiculação de "informações" e entretenimento através de imagens obtidas por câmeras escondidas. A simulação encontra aqui a sedução.

Chegamos, neste ponto, a outra tese jamesoniana relevante na interpretação da atual configuração do universo midiático: sua constituição como esfera pública, ou melhor, como espaço público virtual de apresentação e encenação. Encontramos, em um excerto de sua obra, uma das chaves que podem nos ajudar a caminhar nesta proposição, aperfeiçoando-a.

Comentando a estruturação dos jornais como se fossem seriados, a um só tempo ficcionais e reais, Jameson vislumbra aí a manifestação de um novo domínio da realidade das imagens, relacionando-o a modificações profundas na esfera pública. Este campo híbrido, que se constrói nos interstícios da narrativa e da factualidade, tende à autonomização, uma semiautonomização, como escreve Jameson:

[ele] paira acima da realidade, com a seguinte diferença histórica fundamental: no período clássico, a realidade persistia, independentemente da "esfera cultural" sentimental e romântica, enquanto hoje parece ter perdido essa modalidade de existência em separado (Jameson, 1991:283).

Empiristas às avessas, abandonamos a devoção aos fatos. Nosso objeto de culto é, agora, o altar dos simulacros. Não há mais história, simplesmente uma duração pública, sentenciaria por sua vez Virilio, destilando com amargura o efeito "videográfico" da vida contemporânea, o vivenciar da tele-realidade, espaço de apresentação dos "lugares de imagens" e não mais das "imagens dos lugares" (Virilio, 1990:15). Em tempos de desagregação dos fatos, escreve Virilio, o único veículo percebido como eficaz é a imagem.

Parece-me possível, como pretende este autor, identificar a preponderância da imagem pública em relação ao espaço público, que estaria em vias de ser substituído pela primeira. A percepção dos fatos, ele insiste, dá lugar aos fatos de percepção, a lógica do tudo devassar espraia-se pelos mínimos gestos cotidianos, o impacto televisual sucede o tato e o contato, a teleobservação substitui a observação direta dos fenômenos (Virilio, 1993:14;23;93). O convite ao afastamento, a dessensibilização, a ruptura de laços espaciais, tornando-nos párias de nosso próprio mundo vivido, oferecem a condição de possibilidade para que o "outro", ele próprio, seja convertido em imagem descartável.

Sem receio de exagerar, Virilio (1993:127-132) sugere que a automação da percepção pode estar sendo preparada, dando origem à videônica, à possibilidade de "uma visão sem olhar", na qual "a câmera de vídeo estaria subordinada a um computador", produzindo "imagens virtuais instrumentais" absolutamente enigmáticas a não ser para a própria linguagem maquinal. Se a plausibilidade de tal argumentação só poderá ser aferida em tempos futuros, a delegação à máquina (câmera, aparelho de tevê) da análise da realidade objetiva não é matéria estranha ao momento presente, tele-presente, tele-vigilante.

Virilio (1976) é incisivo ao localizar as correspondências entre superexposição do social e liberação da delação. Segundo escreve, neste processo, fundado na mudança da natureza da troca, constitui-se uma socialidade perversa, uma sorte de ódio coletivo alimentado pela internalização da ameaça. Era das parapolícias, das estruturas paracivis de proteção, mas, também, do controle global, este que tenta antecipar toda ação, e o faz não só através da disseminação de processos eletrônicos de detecção, mas, igualmente, da sobrevalorização dos mínimos incidentes, da criminalização de toda delinqüência menor (Virilio, 1976:229-239).

Indo mais além, Lyotard (1994) fala não só de uma "paixão da abolição", de uma "máquina de guerra" em delírio convulsivo - penetrando no universo da simulação e da dissimulação. Analisando a prática nazista e os desdobramentos psíquicos, sociais e culturais do Holocausto, crê que a "destruição dos despojos" é mais do que uma estratégia defensiva ou autofágica. É "uma 'política' do esquecimento absoluto", onde liquidar não basta, é preciso apagar os vestígios:

Os SS fizeram tudo que era possível para apagar os vestígios do extermínio. (...) Evidentemente, a "política" do extermínio excede a política. Ela não se negocia em uma cena. (...) Essa política apolítica se perpetua depois de "Auschwitz" e seria preciso exterminar os seus meios. E há-os ao menos de dois tipos: uns procedem pelo apagamento, os outros pela representação. Apagamento: os criminosos se travestem de honestos e bons comerciantes ou em chefes de Estado, são "desnazificados" sumariamente, instaura-se um processo de revisão do próprio crime (...). Mas fazer esquecer o crime representando-o é mais apropriado (Lyotard, 1994:36-8).

A segunda alternativa - do extermínio pela repre- 
sentação - é ainda mais instigante, pois, como escreveria Baudrillard, "já não temos a força do esquecimento, nossa amnésia é a das imagens". Mas vejamos o que nos propõe Lyotard:

[o crime] não pode ser representado, a não ser como falha, esquecido de novo, pois desafia as imagens e as palavras. Representar "Auschwitz" em imagens, em palavras, é uma forma de fazê-lo esquecer. (...) Shoah, o filme de Claude Lanzmann, representa uma exceção (...) porque ele não oferece quase nenhum testemunho onde se aponte o irrepresentável do extermínio (...). Representando, inscreve-se na memória, e isto pode parecer uma boa guarda contra o esquecimento. É o contrário, julgo eu. Não se pode esquecer no sentido comum a não ser aquilo que se pôde inscrever, pois então se poderá apagar. (Lyotard, 1994:38).

À amnésia baudrillardiana, contrapõe-se, em Lyotard, a anamnese:

esse extermínio se pretende sem memória, sem vestígio, e assim atesta ainda que mata: há algo de impensável aqui, de tempo perdido sempre aí, uma revelação que não se revela nunca mas está sempre aí, uma miséria. E essa desgraça, essa alma, eis o próprio motivo do pensamento, da procura, da anamnese - da cultura do espírito, como diria Freud: Fortschritt in der Geistlichkeit ${ }^{4}$. Motivo perdido no princípio mesmo do progresso, alma perdida no espírito (Lyotard, 1994:35).

“Eu diria que há hoje uma grande dificuldade de falar da arte e da pintura, porque há uma grande dificuldade de ver, de encontrar o olhar para ver". Baudrillard (1996:213), analisando a arte contemporânea, revela a simbiose entre a estetização da cultura e a mediatização das imagens. "O que nos é dado a ver", ele continua, "não pode ser simplesmente visto, a coisa quer ser visualizada, visualmente absorvida, e circular lá também sem deixar traços". Trata-se, segundo Baudrillard, da "forma simplificada da troca impossível", de um “êxtase sem significação” (Baudrillard, 1996:213).

\section{Nem documental, nem ficcional: o furning point das imagens do cotidiano}

Vamos agora problematizar a natureza dos processos comunicacionais articulados pela produção e consumo de produtos de entretenimento que apelam ao comezinho e ao banal, seja enquanto núcleo temático, seja na constituição de uma linguagem específica, paradigmática dos modos de ver e fazer ver de nossas sociedades, midiáticas, estetizadas e discursivas.

Como recurso interpretativo, distinguirei alguns dos formatos desta operação, embora muitas vezes tais categorias possam se apresentar de modo intercalado ou sobreposto. Temos produtos midiáticos que ficcionalizam a banalidade ou diferentes ações e experiências notadamente cotidianas. Incluímos, de um lado, os flagrantes televisivos obtidos no espaço das ruas, as filmagens de circuitos internos que são publicizadas, as imagens capturadas por redes de televisão através de câmeras ocultas colocadas em via pública. De outro, as infindáveis dramatizações de conflitos familiares em programas de auditório, as reconstituições do dia-a-dia em programas religiosos, a utilização de dinâmicas cotidianas como guias, como ganchos que roteirizam dramatizações da vida "como ela é" em variados produtos seriados de entretenimento.

Outra categoria de representação midiática dá conta de produtos que tornam públicos flagrantes de episódios verídicos da vida íntima, doméstica ou privada que, a princípio, por ela deveriam estar resguardados. São as filmagens domésticas que ganham destaque em quadros de programas televisivos de variedades, são os registros não autorizados de celebridades em atos de "flagrante delito".

\section{Trafegando do mundo dos famosos e das celebridades para aquele da ordinary people, encontramos a estetização de episódios banais ou, ainda, a assumida dramatização de situações cotidianas.}

Contudo, é necessário pontuar que já se tornou ponto pacífico nos estudos da comunicação e nas teorias da mídia a compreensão da irreversível imbricação entre os estatutos ficcional e documental. Interessa-nos com esta afirmação ressaltar que tal efeito de mixagem ou simbiose tem se consolidado, mais do que como uma ferramenta, como um verdadeiro estilo de produção, apresentação e consumo de produtos de entretenimento que tematizam o cotidiano ou se apropriam de cenas do dia-a-dia.

Ao adotar esta postura, evito, pois, recorrer a tradicionais dicotomias. Acredito que o que está em jogo é, ao contrário, a mixagem entre real e ficção, entre presença/ausência, entre proximidade/distanciamento. Com rara astúcia, as imagens do cotidiano, na era da comunicação generalizada, desconhecem fronteiras; não é exatamente a remissão a vínculos espaciais ou a identidades estritamente territoriais que sustenta esta condição de sensibilização ininterrupta.

Torna-se difícil precisar, e esta é uma característica 
destes produtos, os limites entre ficção e documentalidade. Ambos, o "efeito de real" e o "efeito ficcional", tomam parte dos processos de produção e consumo de tais produtos de entretenimento. É exatamente nesta imprecisão, ambivalência ou ambigüidade que reside a sua possibilidade de arrebatamento.

O registro de cenas pouco glamourosas envolvendo personalidades do show-bizz transforma-se em grande sucesso de audiência. Como um Oscar às avessas, a atuação cotidiana e preferencialmente desviante de estrelas do cinema ganha destaque, não por suas características propriamente informativas, mas, fundamentalmente, pelo seu caráter de espetáculo não encenado.

Nada surpreendente se, retomando Morin (2000), notarmos que neste plano da produção imagética somos transportados para um momento mágico, no qual a posse da representação equivaleria - por contigüidade - à posse do representado.

Em uma ponta da sedução, o disfarçado prazer de nos vermos sendo vistos. No extremo complementar do exibicionismo, o fascínio voyeurista experimentado ao nos tornarmos espectadores de imagens geradas através do registro obtido por câmeras ocultas, e em todos os demais nos quais é o outro quem é visto sem que o saiba. O inelutável sucesso dos flagrantes exibidos em programas televisivos apenas confirma e torna exponencial tal encanto. Vivendo da perversão sugerida por esta limiaridade, encontramos igualmente os paparazzi, sequiosos por transformar em imagem pública (on-line) a intimidade off-line de celebridades.

Mas muito antes do estardalhaço motivado pela cartografia obsessiva e endoscópica do cotidiano offline de celebridades através de mídias digitais, diferentes manifestações audiovisuais do comezinho, do banal e do cotidiano já povoavam, crescentemente, nosso universo de produção audiovisual e compunham de modo decisivo nossos processos de constituição imaginária.

\section{0 comezinho e o banal} utilizados como matéria-prima para a produção de visualidades podem se afastar de modo positivo de tentativas de ilustrar a arte através de recuos analíticos.

Trafegando do mundo dos famosos e das celebridades para aquele da ordinary people, encontramos a estetização de episódios banais ou, ainda, a assumi- da dramatização de situações cotidianas. Seja na reconstituição estilizada de crimes, seja na recondução televisivamente mediada de migrantes para a terra natal, o casamento entre imagem e cotidiano e, por suposto, a lógica simbiótica do ficcional/documental, ambos ordenam e fundamentam um tipo de entretenimento que, sabemos, embora se alimente de substratos dramáticos de base popularesca ou popular, possui suficiente força afetual capaz de mobilizar um consumo midiático que ultrapassa, sem sombra de dúvida, demarcações de classe ou pertencimento social.

Outra derivação bastante recorrente do efeito videográfico no registro do cotidiano dá-se pela divulgação de flagrantes do dia-a-dia desde que, retomando um componente que também se percebe no segmento das celebridades, revelem fatos inesperados, inapropriados ou idiossincráticos. Mais uma vez, a duração pública da imagem mediada torna exponencial seus efeitos e mais impactantes seus resultados. Presenciar um tombo, uma escorregada - efetiva ou simbólica - parece de maior desfrute quando re-apresentados. A videografia dos deslizes tanto autoriza o deleite quanto agrava e intensifica o grau de exposição.

Marin Viry (1996), crítico da lógica de produção da linguagem televisa massiva, pode ser útil para explorar características formais de certas apropriações espetacularizadas do comezinho:

A escrita televisual é uma evolução abusiva de sua grande irmã literária: do detalhe, degenerase para o minúsculo. Da redundância, salta-se para o bombardeio. Da comparação escorrega-se para a razão. (...) A querela organizada se transforma, nas mãos do escriba sem fé, numa guerrilha high tech (podemos observar que assuntos cada vez mais minúsculos e isolados do contexto geral tornam-se o alvo preferido). Da relação hierárquica entre o conjunto, o todo e a parte, fica-se apenas com a redução do campo (nota-se a tendência a escarafunchar o assunto como se ele estivesse sendo submetido a uma endoscopia). (...) Escapa-se do ritmo pela descontinuidade sob tensão (o zap) (Viry, 1996).

Ao analisar a entrada das sociedades contemporâneas na "videosfera", sucedânea da era audiovisual, Debray (1993) questiona-se sobre as expectativas que se tem, hoje, em relação às imagens:

Diz-se que "entramos na civilização da imagem". Estranha amnésia. O culto das imagens fabricadas pela mão do homem tem, pelo menos, 10.000 anos. (...) É verossímil que tal poder das imagens foi declinando no decorrer dos tempos e somos talvez nós, na era da televisão, quem acredita menos nessa força. No fundo, desconfiamos cada vez mais de nossas imagens, sejam elas eletrônicas ou não. Entramos na era da suspeição (Debray, 1993:12). 
A tendência a converter e perceber o mundo a partir de signos visuais não leva à defesa incondicional de uma civilização das imagens. Estas, afinal, já foram dessacralizadas. O equívoco de Debray é o de supor que o tipo de relação que se estabelece com as imagens sustente-se em sua suposta "fidedignidade". Não há mais fundamento para esta expectativa. É o próprio corte entre real e imaginário, entre fato e representação que foi redimensionado. $\mathrm{O}$ "contrato de visibilidade" estabelecido com os produtos de entretenimento não passa de fato pela veracidade, mas, ao que tudo indica, pela intensidade da fusão entre fato e ficção.

Reforçando a noção de "desrealização", Henri Pierre Jeudy (1994) atribui aos meios massivos o fundamento deste processo de "alucinação do real", no qual tendem a se dissolver os limites entre imagem e realidade. Na concepção de Jeudy, o processo da produção de imagens midiáticas mantém-nos em uma situação de "televisualização perpétua". A intensidade do visto, a interpelação visual convida os espectadores ao mergulho na tela, mas, também, pode distanciá-los ou, como escreve Jameson, abstraí-los de seus contextos sociais imediatos (Jameson, 1994:137).

\section{0 encanto das emoções baratas}

Vejamos agora alguns contrapontos a este cenário comunicacional. Qual seria a pertinência e o sentido de nomearmos uma tendência observada em parte dos produtos de entretenimento contemporâneos como sendo de "domesticalização", não só em termos de conteúdo, mas igualmente em âmbito formal? O que significa esta tendência quando se fala da produção imagética? Onde o doméstico se associa ao dócil, onde faz rir, onde mais é feroz e impactante? Como e com quais efeitos se utilizam um modo de registro "doméstico" e a tematização das banalidades?

Voltemos nossa atenção a outra dimensão da representação de banalidades: o que ela significa de celebração, tecendo uma fantástica epifania do comezinho. Rejeitam-se neste caso interpretações que ressaltam o que seria um caráter de per si pernicioso do entretenimento, ao compreendê-lo como estratégia fantasiosa massiva ou maciça de adestramento de públicos ociosos e ao compreender público, fantasia e ócio como necessariamente negativados e merecedores do esforço e da ação intelectual do esclarecimento.

$\mathrm{Na}$ consciência da finitude e na busca de sua superação são as imagens nossas primordiais e principais mediadoras. Neste encantador exercício do logo aqui e do nunca agora, o mais comezinho adquire a qualidade de espelho de magnitude, esta paixão feliz que faz do encontro com o banal um exercício humano, demasiado humano de imortalidade. As imagens do cotidiano povoam nosso mortal universo de uma aura de significação memorial, esta que nos faz amplamente disponíveis ao espetáculo de encenar com soberania o que, em nós, resta de verdadeiramente inacabado e irremediavelmente disperso.

O mais belo espetáculo é o espetáculo das banali- dades. Analisando o encanto que cerca as imagens, Edgar Morin (1997) postula que nada nos é mais sedutor do que a transformação do banal e do comezinho em registro imagético. Um duplo sentido cerca a "impressão de realidade" desta forma obtida, seja na fotografia, no cinema e, mais recentemente, na televisão e nas mídias digitais, embora estas últimas não tenham sido, no texto citado, abordadas pelo autor. Morin, explorando a transformação do já visto em imagem - em espetáculo de imagens -, destaca do processo a experiência da fotogenia, esta "qualidade que reside, não na vida, mas na imagem da vida" (Morin, 1997, 33).

Há uma humanização intrínseca a estas imagens do cotidiano. Explorando as interfaces e tensões entre imagens do cotidiano e representações imagéticas, percebemos outra nuance do que seria uma tendência à "domesticalização" de temas e modos de registro visuais. Segundo propomos, falar, desde este ponto de vista, de uma imagética de banalidades, significa falar de imagens localizadas em zonas limiares ou limítrofes.

Aproximar do universo da limiaridade e do limítrofe a concepção de um entretenimento fundado nas banalidades é uma tomada de lugar a um só tempo conceitual e epistemológico. Significa ainda localizar, em estado de tensão limiar, o continuum que trafega por entre os campos da produção, da recepção e da interpretação midiática, colocando-os em estado de debate.

Com esta argumentação, o comezinho e o banal utilizados como matéria-prima para a produção de visualidades podem se afastar de modo positivo de tentativas de ilustrar a arte através de recuos analíticos que de algum modo busquem, por falta de melhor palavra, enobrecer o espetáculo das emoções baratas. Neste sentido, entendemos a representação do comezinho também como condição de possibilidade para a permanência de uma resistência simbólica.

Entender o valor das banalidades, privilegiando as conexões e tensões observadas entre imagens do cotidiano e representação imagética, não significa, contudo, descartar o questionamento acerca da estetização do banal, dos sentidos possíveis da inserção do comezinho em dinâmicas de espetacularização e de "domesticalização", tão caras a uma sorte de sedução apaziguadora da recepção presente em parte dos produtos midiáticos massivos. mfamecos

\section{NOTAS}

1. Refiro-me à tese jamesoniana, que será analisada no decorrer deste texto.

2. Apelido de Vitangelo Moscarda, dado por sua mulher, Dida.

3. Segundo Virilio, vivemos em um regime dromocrático, uma ditadura da movimentação compulsória. 
4. "Progresso na espiritualidade", na tradução de Ciro Marcondes Filho.

\section{REFERÊNCIAS}

BAITELLO JR., Norval. As quatro devorações: iconofagia e antropofagia na comunicação e na cultura. Compós 2002. Paper apresentado na Reunião Anual. GT Comunicação e Cultura. Rio de Janeiro, ECO/UFRJ, 2002.

BAUDRILLARD, Jean. A arte da desaparição. Rio de Janeiro, UFRJ, 1997.

BAUDRILLARD, Jean. A transparência do mal: ensaio sobre fenômenos extremos. Campinas, Papirus, 1992.

DEBRAY, Régis. O Estado sedutor. As revoluções midiológicas do poder. Petrópolis, Vozes, 1993.

DELEUZE, Gilles e GUATTARI, Félix.

"Micropolítica e segmentaridade". In: Mil

Platôs. Capitalismo e esquizofrenia, Vol. 3. Rio de Janeiro, Editora 34, 1996, pp. 83-115.

ENZENSBERGER, Hans Magnus. Entrevista a Forum Deutsch. Revista Brasileira de Estudos Germânicos, nº 1, 1996, p. 7. (Trad. Ciro Marcondes Filho).

ENZENSBERGER, Hans Magnus. Guerra civil. São Paulo, Companhia das Letras, 1995.

JAMESON, Fredric. As marcas do visível. Rio de Janeiro, Graal, 1995.

JAMESON, Fredric. Espaço e imagem. Rio de Janeiro, UFRJ, 1994.

JAMESON, Fredric. Pós-modernismo. A lógica cultural do capitalismo tardio. São Paulo, Ática, 1996.

JEUDY, Henri Pierre. "Pesquisador dos processos mediáticos”. In: RAMOS, Sílvia (org.). Seminário Mídia E Violência Urbana. Relatos. Rio de Janeiro, FAPERJ, 1994, pp. 67-78.

KROKER, Arthur e COOK, David. The postmodern scene: excremental culture and hyper-aesthesis. Montréal, New World Perspectives, 1991.

LYOTARD, Jean-François. Heidegger e "os judeus". Petrópolis, Vozes, 1994.

MORIN, Edgard. O cinema ou o homem imaginário. Lisboa, Relógio D’Água, 1997.
PARENTE, André (org.). Imagem-máquina. A era das tecnologias do virtual. Rio de Janeiro, Editora 34, 1993.

PIRANDELLO, Luigi. Um, nenhum e cem mil. São Paulo, Cosac \& Naify, 2001.

ROCHA, Rosamaria Luiza (Rose) de Melo. "Imagens limiares e seus fabulosos fabuladores". Niterói, 2005. Trabalho apresentado ao Grupo de Trabalho "Comunicação e Cultura", do XIV Encontro da Compós.

ROCHA, Rosamaria Luiza (Rose) de Melo. "Sorria, você está sendo estetizado! Apontamentos sobre imagem e cotidiano na indústria do entretenimento". Curitiba, UTP, 2007.

Trabalho apresentado ao Grupo de Trabalho "Mídia e Entretenimento", do XVI Encontro da Compós.

ROCHA, Rosamaria Luiza (Rose) de Melo. “Você sabe para quem está olhando? Visibilidade e incomunicabilidade na cultura contemporânea". In. BAITELLO, Norval (org.) Os meios da incomunicação. São Paulo, Annablume, 2005.

ROCHA, Rosamaria Luiza (Rose) de Melo. Da amnésia à anamnese: linguagens e pedagogia da violência nos media e nos centros urbanos brasileiros. Pesquisa de pós-doutoramento. Relatórios I e II. Programa de Estudos PósGraduados em Ciências Sociais/PUC-SP. São Paulo, 1999 e 2000.

VIRILIO, Paul. A inércia polar. Lisboa, Dom Quixote, 1993.

VIRILIO, Paul. A máquina de visão. Rio de Janeiro, José Olympio, 1994.

VIRILIO, Paul. L'insecurité du territoire. Paris, Galilée, 1993.

VIRY, Marin. “Notas sobre escrita ou linguagem televisual". O Estado de S. Paulo, 10 de outubro de 1996. 